\title{
Bounded Learning-by-Doing and Sources of Firm Level Productivity Growth in Colombian Food Manufacturing Industry
}

\author{
Apurba Shee and Spiro E. Stefanou
}

\begin{abstract}
This paper models the bounded learning concept with the learning progress function characterized by the degree of efficiency and the specification of the learning progress as a logistic function capturing both the slow start-up and the limit in learning progress. We differentiate learning efficiency from the technical efficiency. The endogeneity corrected stochastic frontier model is then used to decompose the factor productivity growth into components associated with technological change, technical efficiency, scale, and learning. This productivity growth decomposition provides useful information and policy level insight in firm-level productivity analysis. Empirical results based on plant-level panel data on the Colombian food manufacturing industry for the period 1982-1998 suggest that productivity growth not only stems from technical progress, technical efficiency change, and scale but also from significant learning effect. The relative importance of the productivity growth components provides perspective for efficient resource allocation within the firm.
\end{abstract}

JEL classification: D24, O47, C23

Keywords: Colombian food manufacturing industry, Bounded learning-by-doing, Endogeneity corrected stochastic frontier, Firm-level productivity growth, Decomposition of productivity growth

\section{Contact Author:}

Apurba Shee

International Food Policy Research Institute

a.shee@,cgiar.org; shee.apurba@gmail.com

Apurba Shee is Associate Research Fellow, Environment and Production Technology Division, International Food Policy Research Institute and Spiro E. Stefanou is Professor and Chair, Food and Resource Economics Department, University of Florida and Visiting Professor, Business Economics Group, Wageningen University (Netherlands). 


\section{Introduction}

The measurement of productivity dispersion has been the focus of decades-long interest in the scholarly literature and among policy makers. In addition to broad structural forces driving productivity changes, there is more recent interest in measuring and identifying the heterogeneous forces driving these changes. A major force is learning-by-doing which is used by economists to describe the phenomenon of productivity growth arising from the accumulation of a firm's production experience. Production experience yields information that can be translated into knowledge, which improves decisions and results in productivity enhancement. This learning-bydoing process can also lead to a reduction in the future cost of production. The costless by-product of a firm's production activity is passive learning (Rosen, 1972) and the firm's productivity enhancement process in this case is an experience curve. The observed relationship of productivity (or unit cost) being an increasing (or decreasing) function of cumulative output is the progress curve, where productivity growth is the result of not only passive learning but also a variety of forces encouraging growth such as research, training, capital investment and other unmeasured factors. The productivity gain arising from learning is used as a long-run planning and control tool in a variety of manufacturing industries.

The classical learning progress assumes that learning is unbounded and represented by a productivity and cumulative experience power relation. Considerable empirical research uses the log-linear model to estimate the unbounded learning rates and finds a significant relationship between firm productivity and production experience. Empirical studies find that firms and industries become more productive as they gain more experience of producing goods and services (Arrow, 1962; Rapping, 1965; Lieberman, 1984; Bahk \& Gort, 1993; Lucas Jr, 1993; Luh \& Stefanou, 1993; Irwin \& Klenow, 1994; Jarmin, 1994; Benkard, 2000; Thompson, 2001; Thornton 
\& Thompson, 2001). The results from this body of work are varied and, on average, find an approximately 10 to 20 percent reduction in the average cost of production for every doubling of cumulative output. But are the gains from learning unbounded?

Organizational knowledge through experience is embedded in individual workers, technology, and structure of the organization. When passive learning is the dominant factor in learning process, productivity growth is invariably bounded (Rosen, 1972). Conway and Schultz (1959), Jovanovic and Nyarko (1995), Baloff $(1966,1971)$ and Young $(1993$, p. 445) present evidence that productivity reaches a limit, or a "plateau effect". The recognition of the S-shaped learning curve has a long history, having appeared in the literature as early as Carr (1946) and has been useful for planning and control methods for new product introduction. Cochran (1960) also proposes the learning curve as S-shaped, suggesting that this pattern appears to be more appropriate than the classical learning model. The proposition is that during the early stage a firm attempts various options, and explores alternative production plans and designs which slow down the initial learning rate. After the initial exploration there are fewer changes in the production system leading to a higher learning rate (Cochran \& Sherman, 1982). Both the learning bound and its S-shape character are important in the sense that the learning limit captures the diminishing return of learning a given technology and the S-shape replicates the start-up phase of a firm.

Differences in management, training, and infrastructure lead to varied learning abilities across firms, even though different firms may share similar experiences and produce the same types of products (Adler \& Clark, 1991; Argote, 1999). Hence, the proposition underlying this study is that the observed productivity and accumulated experience relationship is the effect of both the passive learning and the management and training effort. We attempt to quantify the 
heterogeneous learning ability inherent across firms in an industry by introducing the notion of learning inefficiency. We define inter-firm learning inefficiency as the inability of a firm to reach the optimal plateau relative to the 'best firm' from a set of comparable firms. We discern the technical inefficiency from the learning inefficiency by characterizing the deviation of a firm's operation from the production frontier given a level of learning as technical inefficiency, while a deviation of a firm's learning progress from the optimal progress curve given a level of technical efficiency is measured as a consequence of learning inefficiency. We characterize the learning progress function by the degree of efficiency and specify as a logistic function capturing both the slow start-up and the limit in learning progress. This specification overcomes the limitation posed by the classical learning curve literature.

Although the 'Solow residual approach' assumes technical change is the unique source of productivity growth, recent literature acknowledges that along with technical change, change in efficiency (both technical and allocative) and scale can contribute to productivity growth (Nishimizu \& Page, 1982; Bauer, 1990; Kumbhakar, 2000; Kim \& Han, 2001). We decompose total factor productivity growth into components associated with learning, scale, technical efficiency, technological change and change in allocative efficiency. This productivity growth decomposition can provide useful information and policy level insight in firm-level productivity analysis.

This study aims at contributing to the literature on measuring the sources of firm-level productivity growth that includes not only technological progress, technical efficiency change, and scale but also the impact of bounded learning that can provide direction for policy making on firm performance. We draw on a 17-year micro data series as we investigate learning, efficiency and 
productivity growth on the Colombian food manufacturing industry. This study develops framework for decomposing productivity change that accommodates the contribution of the learning effect by using the endogeneity corrected stochastic production frontier approach (Shee and Stefanou, 2015). This paper extends the conventional learning model by incorporating the bounded learning concept with the learning progress function characterized by the degree of efficiency. Finally, by identifying the relative importance of various productivity growth components this research contributes to decision making for efficient resource allocation within a firm.

The next section presents the concepts of a bounded learning progress function and learning inefficiency, how to distinguish learning inefficiency from technical inefficiency, followed by the presentation of the analytic framework for productivity growth decomposition where the learning effect is a source of productivity growth. Then the structural estimation methodology using the endogeneity corrected stochastic production frontier is presented. The next section describes the firm-level panel data of the Colombian food manufacturing industry, followed by estimation results. The final section provides policy implications and conclusions drawn from the study.

\section{Bounded learning progress and learning inefficiency}

Learning-by-doing is an empirical phenomenon of productivity growth associated with accumulated production experience by a firm. However, learning progress is not costless as it involves increased management, training, and infrastructure to lead to better firm learning abilities. The plant-level heterogeneity in productivity gains associated with learning-by-doing can be captured through the concept of learning efficiency. Stochastic Frontier Analysis is a common approach to analyze relative efficiency of economic units and when a firm operates on the 
production frontier, the firm is called technically efficient and a deviation from the frontier is the measure of technical inefficiency of the firm. On the other hand, when a firm achieves the maximum feasible productivity due to given production experience, the firm is said to be learning efficient and a deviation from the optimal progress curve is measured as the level of learning inefficiency. A firm might face both inefficiencies simultaneously. The challenge then arises, how to disentangle these two inefficiencies?

The conventional learning model assumes that the productivity increases with firm's cumulative output and persists indefinitely with production experience (Arrow, 1962; Rapping, 1965; Lieberman, 1984; Bahk \& Gort, 1993; Irwin \& Klenow, 1994; Jarmin, 1994; Benkard, 2000; Thompson, 2001). Following the arguments similar to Cochran (1960) and Cochran and Sherman (1982), we extend the conventional learning model by modeling learning progress as a logistic function which explains three stages (slow start-up, acceleration, and plateau) of learning progress concept. It is important to note that with a given technology firms gain expertise that allows them to operate the technology more efficiently. Once the productivity gain due to learning on a particular technology is exhausted, further growth in productivity can only be achieved by moving to improved technology. However, firms incur a cost when they adopt an advanced technology. The more advanced the adopted technology, the less the firm's current learning will be relevant to operate in new technology. Hence, firms face a tradeoff in the choice of technology (Malerba, 1992; Jovanovic and Nyarko, 1996). The limit on learning also depends on the firm decisions whether to retain the old technology to gain a learning advantage and avoid the cost associated with switching to a new technology, or continuous switching to new technologies to obtain long- 
run growth. Even though learning progress can rise and fall in the short run, the smooth S-shaped envelope of productivity with respect to cumulative past output results over the long run.

We specify the logistic differential equation to represent the productivity-experience relationship. As the firm produces more and more of a product it increases its stock of knowledge according to the differential equation

$$
\frac{d A}{d V}=\alpha A-\frac{\alpha}{\bar{a}} A^{2}
$$

with the explicit solution as

$$
A=\frac{\bar{a}}{1+\left(\frac{\bar{a}-a_{0}}{a_{0}}\right) \exp (-\alpha V)}
$$

where $A$ is productive knowledge arising through experience, $V$ is cumulative production, $A(V=0)=a_{0}$ is the initial (known) state of knowledge and denotes the height of the progress curve at $V=0, \alpha>0$ is instantaneous learning rate, and $\bar{a}$ is the upper bound of the state of knowledge (the production potential) and denotes the height of the progress curve at $V \rightarrow \infty$.

Training and research, quality of the personnel and infrastructure are some reasons why some firms learn faster than others. The question is then can we measure the difference in learning abilities in a cohort of firms having identical initial productivity or the state of knowledge? The difference between the learning progress curve of any firm and that of the 'best practice firm' is defined as inter-firm learning inefficiency which reflects the inability of a firm to reach the optimal production potential. The logistic differential equation for a general firm with a level of learning inefficiency $\eta$ can be written as 


$$
\frac{d A}{d V}=\alpha A-\frac{\alpha}{\bar{a}} A^{2}-\eta \alpha A
$$

with the explicit solution is (see Appendix A)

$$
A\left(V_{t}\right)=\frac{(1-\eta) \bar{a}}{1+\frac{(1-\eta) \bar{a}-a_{0}}{a_{0}} e^{-\alpha(1-\eta) V}}
$$

where $\eta$ is the level of firm-specific learning inefficiency which prevents the firm from reaching the learning progress of the 'best practice firm' for any V. For the purposes of exposition for the core concept, we expect $\eta \in[0,1)$ and is time-invariant but these restrictions can be relaxed. ${ }^{1}$ The inclusion of the learning inefficiency term identifies $\eta$ as having an impact on both the intrinsic learning rate $(\alpha(1-\eta))$ and the learning bound $((1-\eta) \bar{a})$ for a general firm. The functional representation of the general firm should always be below the learning progress function of the best practice firm for all values of $V^{2}$. Conceptually, the effect of learning inefficiency on both the intrinsic learning rate and the learning bound is monotonic which is important to capture the heterogeneous learning abilities among firms producing same level of cumulative output in a

\footnotetext{
${ }^{1}$ In fact, $\eta$ is a firm-specific component that can vary over time and can reflect changes in the rate of learning. But one should not necessarily exclude the prospect of firm's unlearning or forgetting.

${ }^{2}$ The differential equation representing the learning progress function of a general firm (with learning inefficiency) is $\frac{d A_{1}}{d V}=\alpha A-\frac{\alpha}{\bar{a}} A^{2}-\eta \alpha A$, and for the best practice firm is $\frac{d A_{2}}{d V}=\alpha A-\frac{\alpha}{\bar{a}} A^{2}$. The difference is $\frac{d}{d V}\left(A_{1}-A_{2}\right)=-\eta \alpha A$. since $\mathrm{A}>0, \eta \in[0,1)$ and $\alpha>0$, the above derivative is always negative which proves
} that the function of the general firm will always be below that of the best practice firm for any value of $\eta \in[0,1)$. 
homogenous manufacturing sector. These two effects will ensure that a less learning efficient firm will have a slower learning growth and quick learning saturation resulting in overall low learning effect on productivity growth. The level of inefficiency $\eta$ for a firm may be a function of research and training, infrastructure of the firm, and some unmeasured factors. Appendix B presents a simulated plots of the learning progress function of a general firm with different values of the inefficiency level in learning. The upper bound of learning progress is assumed to be 1 or $\bar{a}=1$.

Understanding the difference between maximum potential frontier and potential frontier given learning is important to distinguish between learning and technical inefficiency. The learning inefficiency parameter $\eta$ is firm specific and reflects the inability of a firm to reach the learning progress curve of the 'best practice firm' given a set of cumulative past output. The deterministic kernel of the potential production frontier given learning can be represented as $A\left(V_{t} ; \eta=\eta_{i}\right) f(x, t ; \beta)$. The maximum potential frontier is the production frontier of the best learning progress (100\% learning efficient) firm and can be represented as $A\left(V_{t} ; \eta=0\right) f(x, t ; \beta)$.

Figure 1 depicts the deterministic production function of both the maximum potential frontier and potential frontier given learning for a single product and one-variable factor of production. Point A depicts a firm producing $y_{t}$ using input $x_{t}$ is technically inefficient (from an output orientation) because it operates beneath the potential production frontier given learning and the deviation $\mathrm{AB}$ is measured as technical inefficiency. The impact of learning inefficiency for the firm is represented by the deviation of the potential frontier given learning from the maximum potential frontier or $\mathrm{BC}$. 


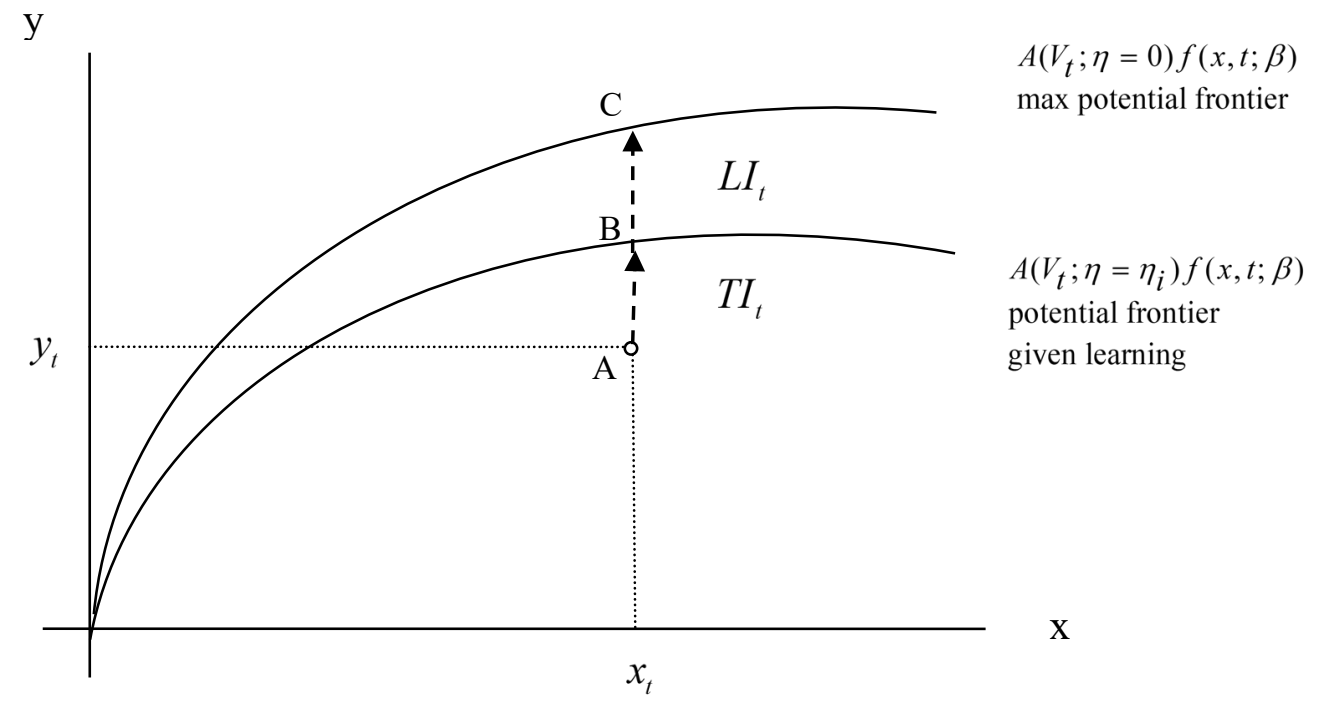

Figure 1: Technical inefficiency and learning inefficiency

Technical inefficiency reflects the inability of a firm to obtain the maximum potential output given learning, from a given input allocation. Technical efficiency (TE) compares the actual quantity of output achieved to the maximum achievable output for certain inputs given the constant learning inefficiency for the firm

$$
T E_{i}=\frac{y_{i t}}{A\left(V_{t} ; \eta\right) f\left(x_{i t} ; \beta\right) e^{v_{i t}}}=\left.e^{-u_{i t}}\right|_{\eta=\eta_{i}}
$$

Increased education and managerial ability are widely accepted sources of technical efficiency in a firm. Leibenstein's characterization of technical efficiency as X-inefficiency (see Leibenstein, 1966; Stigler, 1976; Leibenstein, 1978, 1979) involves a theory where the difference in motivation among decision makers was considered the source of inefficiency. He also points out that differences in knowledge among the firms can lead to firm inefficiency. Mundlak's (1961) 
covariance analysis to control for managerial bias in production reflects a positive relation between managerial ability and technical efficiency. Similarly, Stefanou and Saxena (1988) find a significant impact of education and training on allocative efficiency by a non-frontier approach to efficiency. Battese and Coelli (1995) find that age and schooling have a positive and negative effect on inefficiency, respectively.

If the source of technical inefficiency is the difference in motivation, efficiency can be improved by introducing appropriate incentives. If the difference in knowledge reflects the level of technical inefficiency, its improvement is influenced by a sustained learning process suggesting that learning inefficiency can lead to technical inefficiency. Hence, learning inefficiency can be attributed as a source of technical inefficiency. Learning efficiency allows some firms to benefit more than others from an equivalent level of experience (cumulative volume of past output), and reflects the failure of a firm to obtain the maximal state of knowledge achievable from the given amount of experience. The firm-specific learning inefficiency parameter, $\eta$, can be estimated from the learning progress function where $(1-\eta)$ is the measure of learning efficiency. The learning effect can be realized by the ratio of the actual quantity of output achieved given firm-specific learning to the output achieved by the best learning practice firm given a level of technical efficiency

$$
L E_{i}=\left.\frac{A\left(V_{t} ; \eta=\eta_{i}\right) f(x, t ; \beta)}{A\left(V_{t} ; \eta=0\right) f(x, t ; \beta)}\right|_{T E}
$$

The productivity gain due to learning is not automatic or a costless by-product of experience. Sources of firm-specific learning inefficiency are attributed typically to investments in research, training, and infrastructure which impacts both the intrinsic learning rate and learning inefficiency. 
While technical inefficiency varies with time, the learning inefficiency parameter is constant for a firm. However, as productivity varies with cumulative past output, the effect of learning on production changes over time. The technical efficiency and learning effect over time are illustrated in figure 2, in which a single input is used to produce a single output, and a firm moves from $\left(x_{t_{1}}, y_{t_{1}}\right)$ at time $t_{1}$ to $\left(x_{t_{2}}, y_{t_{2}}\right)$ at time $t_{2}$. The technical inefficiency level changes from time $t_{1}$ to $t_{2}$, and at $t_{2}$ it is measured as the deviation of the production point from the new potential frontier given learning $A\left(V_{t_{2}} ; \eta=\eta_{i}\right) f\left(x, t_{2} ; \beta\right)$. The effect due to learning inefficiency is captured by the difference between this potential frontier to the maximum potential frontier $A\left(V_{t_{2}} ; \eta=0\right) f\left(x, t_{2} ; \beta\right)$ at time $t_{2}$.

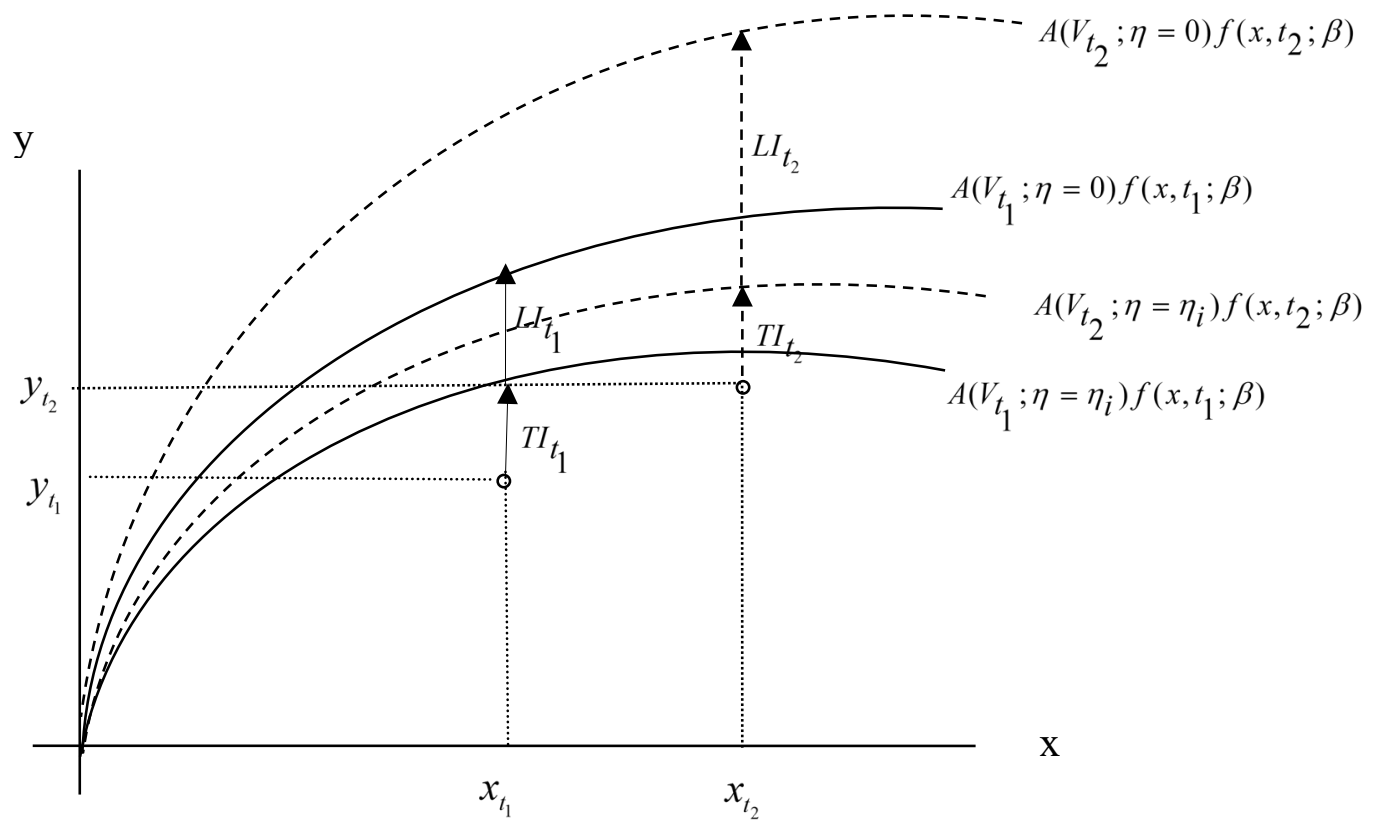

Figure 2: Technical inefficiency and learning effect over time

Notice that the maximum potential frontiers at the two time periods will be the same if the cumulative volume of the output is such that the learning progress function approaches a plateau. 
These two definitions are based on two different reference points; one is the deviation from the production frontier given learning and the other is the deviation from the progress curve of the 'best practice firm'. A firm might face both inefficiencies simultaneously. The changes in both the technical efficiency and learning progress contribute to firm productivity growth.

\section{Analytical framework for productivity growth decomposition}

Literature on productivity growth decomposition acknowledges that along with technical change, change in efficiency (both technical and allocative) and scale can contribute to productivity growth (Denny, Fuss, \& Waverman, 1981; Nishimizu \& Page, 1982; Bauer, 1990; Kumbhakar, 2000; Kim

\& Han, 2001). But what's not addressed is the contribution of learning in productivity growth decomposition. To make the productivity measure invariant to the intensity of the factor use, the concept of total factor productivity (TFP) is used. TFP is represented by the often-used formulation of production function where output is the product of a function of inputs and a Hicks-neutral shifter. The stochastic production frontier (assuming no data noise) with Hicks-neutral shifter is written as

$$
y_{i t}=A\left(V_{i t}\right) f\left(x_{i t}, t\right) e^{-u_{i t}}
$$

where $y_{i t}$ is the scalar output of $i^{\text {th }}$ firm at time period $\mathrm{t}(\mathrm{i}=1, \ldots \ldots, \mathrm{N}$ and $\mathrm{t}=1, \ldots \ldots, \mathrm{T}), \mathrm{x}$ is input vector, the shifter $A\left(V_{t}\right)$ is the TFP contribution due to learning progress, and $u_{i t} \geq 0$ reflects the technical inefficiency or the gap between frontier technology (or potential frontier given a level of learning) and a firm's actual production output. Totally differentiating output with respect to time, and denoting ' $\dot{z}$ ' as the rate of change or its logarithmic time derivative, we obtain 


$$
\dot{y}=\frac{1}{A(V)} \frac{d A}{d V} \frac{d V}{d t}+\frac{\partial \ln f(x, t)}{\partial t}+\sum_{j} \frac{\partial \ln f(x)}{\partial x_{j}} \frac{d x_{j}}{d t}-\frac{d u}{d t}
$$

The first term on the right-hand side of (8) measures the change in output growth contribution due to learning. The second and third terms measure the change in output driven by technical progress (TP) and by change in input use, respectively. The fourth term captures the change in technical inefficiency. Hence, the overall change in production is not only affected by technical progress, changes in input use, and change in technical inefficiency, but also by the change in learning progress. Using $T P=\frac{\partial \ln f(x, t)}{\partial t}$ and the equation of motion in (3), (8) is rewritten as

$$
\dot{y}=\frac{1}{A}\left(\alpha A-\frac{\alpha}{\bar{a}} A^{2}-\eta \alpha A\right) y+T P+\sum_{j} \varepsilon_{j} \dot{x}_{j}-\frac{d u}{d t}
$$

where the change in the frontier output due to the change in input use or the output elasticity of input $\mathrm{j}$ is $\varepsilon_{j}=\frac{\partial \ln f(x)}{\partial \ln x_{j}}$. Total factor productivity growth is defined as output growth less input growth, where input growth accounts for all factors of production. With total factor productivity defined as output growth less input growth, using

$$
\dot{T F P}=\dot{y}-\sum_{j} s_{j} \dot{x}_{j}
$$

where input growth is the sum of the growth of all inputs weighted by their respective cost shares (Denny, et al., 1981), the total factor productivity growth in (10) can be expanded to

$$
\dot{T F P}=\left(\alpha-\frac{\alpha}{\bar{a}} A-\eta \alpha\right) y+T P-\frac{d u}{d t}+\sum_{j}\left(\varepsilon_{j}-s_{j}\right) \dot{x}_{j}
$$


The share of marginal product of input $j=\lambda_{j}=\frac{f_{j} x_{j}}{\sum_{k} f_{k} x_{k}}=\frac{\varepsilon_{j}}{\sum \varepsilon_{k}}$ since $\varepsilon_{j}=\frac{d f}{d x_{j}} \frac{x_{j}}{f}=f_{j} \frac{x_{j}}{f}$ Replacing $\varepsilon_{j}=\lambda_{j} \sum \varepsilon_{j},(11)$ yields

$$
\dot{T F P}=\left(\alpha-\frac{\alpha}{\bar{a}} A\right) y-\eta \alpha y+T P-\frac{d u}{d t}+\sum_{j}\left(\lambda_{j} \sum \varepsilon_{j}-s_{j}\right) \dot{x}_{j}
$$

Rearranging the terms and using the definition of returns to scale $\left(R T S=\sum_{j} \varepsilon_{j}\right),(12)$ is written as

$$
T \dot{F P}=\alpha y\left(\tilde{\eta}-A_{i t}\right)+T P-\frac{d u}{d t}+\sum_{j} \lambda_{j} \dot{x}_{j}(R T S-1)+\sum_{j} \dot{x}_{j}\left(\lambda_{j}-s_{j}\right)
$$

where $\tilde{\eta}=(1-\eta)$ is learning efficiency. Hence, productivity growth is influenced by technical progress, learning inefficiency, technical inefficiency, and components related to input use (namely, the scale and allocative efficiency effects). Technical inefficiency falling $\left(\frac{\partial u}{\partial t}<0\right)$ means technical efficiency increases over time or the production point becomes closer to the frontier. The first and second components of (12) represent growth and decay in knowledge absorption, respectively, and thus, reflect the net knowledge growth accounting for the ability to absorb knowledge. The last component of (13) presents the allocative efficiency effect which actually depicts the inefficiency in allocating resources resulting from the deviation of input prices from the value of their marginal product. In all, productivity change is decomposed into changes in efficiency, both technical and allocative efficiency, change in learning progress, technical change, and change in scale. The first is measured by how far the firm is from the production frontier given learning, the second by the inability of the firm in allocating resources resulting from the deviation of the input prices from the value of their marginal product, the third by net 
knowledge growth due to learning, the fourth by the shift in the frontier, the last by the movement of the firm along the curvature of the production frontier.

\section{Structural econometric estimation}

Consider a firm operating in a competitive market that has production function

$$
y=F\left(X(t), K(t), A\left(V_{t}\right), t\right)
$$

where $X(t)$ is vector of variable inputs and $K(t)$ is a vector of quasi-fixed inputs like capital, and $A\left(V_{t}\right)$ is learning progress function reflecting a productivity enhancing factor. How $A\left(V_{t}\right)$ enters the production function depends on the nature of the learning progress function. The question is does $A\left(V_{t}\right)$ embody the inputs or the organization? Bahk and Gort (1993) decompose the firm specific learning by doing into labor, capital and organizational learning by modeling learning component as (1) separate arguments in labor and capital augmenting term and (2) productivity shift parameter (also see Rapping, 1965). The production frontier for a sample of $\mathrm{N}$ firms for $\mathrm{T}$ time periods, can be written as

$$
y_{i t}=A\left(V_{i t}\right) f\left(x_{i t}, t ; \beta\right) e^{v_{i t}-u_{i t}}
$$

$y_{i t}$ denotes production of $i^{t h}$ firm at time period $\mathrm{t}, x_{i t}$ is a vector of input quantities of $i^{\text {th }}$ firm at $\mathrm{t}$ time period, $\beta$ is a vector of unknown parameters to be estimated, $v_{i t} \sim N\left(0, \sigma_{v}^{2}\right)$, and $u_{i t} \sim N^{+}\left(0, \sigma_{u}^{2}\right) . A(V)$ is a scaling factor reflecting the state of organizational knowledge which depends not only on experience (cumulative volume of output) but also on learning efficiency for 
a firm. Following (11), a Cobb-Douglas production frontier with time variant technical efficiency can be written in $\log$ form

$$
y_{i t}=\beta_{0}+\beta_{l} l_{i t}+\beta_{m} m_{i t}+\beta_{e} e_{i t}+\beta_{k} k_{i t}+\delta t+a_{i t}+v_{i t}-u_{i t}
$$

where $y$ is $\log$ output quantity produced, $l, \mathrm{~m}, e$, and $k$ are the log of labor, material, energy, and capital inputs, respectively, $a$ is the $\log \mathrm{A}$, and $\beta_{l}, \beta_{m}, \beta_{e}$, and $\beta_{k}$ are the their respective coefficients. Exogenous technical change is represented by $t$, technical inefficiency is represented by $u$, and $v$ is random statistical noise.

It is well documented in the literature (Marschak \& Andrews, 1944; Griliches \& Mairesse, 1995; Olley \& Pakes, 1996; Levinsohn \& Petrin, 2003; Ackerberg, Caves, \& Frazer, 2006,2007) that quantities of inputs are likely to be correlated with productivity shocks if a firm observes some part of its productivity and efficiency leading to a biased estimate of production function parameters. Using the same argument, Shee and Stefanou (2015) raise the concern of endogeneity issue in stochastic production frontier estimation and develop a two-stage estimation methodology to correct for endogeneity issue in the stochastic frontier model. Adapting the Levinsohn and Petrin (2003) method of using intermediate input as a proxy to control for unobserved productivity shock, consistent estimates of the production parameters and technical efficiency are generated. In the first stage, coefficients of freely variable inputs except the intermediate proxy input along with technical efficiency are estimated using a semiparametric approach. In the second stage, the parameters of the proxy input and capital are estimated using the Generalized Method of Moments (GMM) given all estimated parameter values obtained in the first stage. The details of the 
estimation approach of the endogeneity corrected stochastic production frontier model are presented in Shee and Stefanou (2015).

The productivity term can be recovered from the residual using the estimated coefficients obtained from the estimation of the endogeneity corrected stochastic frontier model,

$$
\hat{A}_{i t}=\exp \left(y_{i t}-\hat{\beta}_{0}-\hat{\beta}_{l} l_{i t}-\hat{\beta}_{m} m_{i t}-\hat{\beta}_{e} e_{i t}-\hat{\beta}_{k} k_{i t}-\hat{\delta} t\right)
$$

which can be viewed as unexplained residual ${ }^{3}$. Using the estimated parameter values of the endogeneity corrected stochastic frontier model, the decomposition of productivity growth following (13) is presented below

1) The learning effect $L E=\dot{A}$.

2) Rate of technical progress $T P=\frac{\partial \ln f\left(x_{i t}, t\right)}{\partial t}=\delta$.

3) Technical efficiency change can be obtained by $T E C=-\frac{\partial u_{i t}}{\partial t}$, where

$$
u_{i t}=T E_{i t}=E\left(\exp \left(u_{i t}\right) \mid v_{i t}-u_{i t}\right)
$$

\footnotetext{
${ }^{3}$ Instantaneous learning rate $\alpha$ and learning inefficiency $\eta$ can be estimated from this residual by representing (3) as $\frac{d \hat{A}}{d V}=\alpha \hat{A}-\frac{\alpha}{\bar{a}} \hat{A}^{2}-\eta \alpha \hat{A}$. Using the discrete analogue of the derivative term $\frac{d \hat{A}}{d V}=\frac{\hat{A}_{i t}-\hat{A}_{i t-1}}{\hat{y}_{i t}}$, (3) can be written as $\frac{d \hat{A}_{i t}}{\hat{y}_{i t}}=\sum\left(\alpha_{i}-\eta_{i} \alpha_{i}\right) D_{i} \hat{A}_{i t-1}-\sum \alpha_{i} D_{i} \hat{A}_{i t-1}^{2}+\varepsilon_{i t}$, where $D_{i}$ is a dummy variable for individual firm in a sector. Using this specification instantaneous learning rate and learning inefficiency parameters can be estimated by using the nonlinear least square technique.
} 
4) To find the change of scale component, output elasticity with respect to $j$-th input is defined by $\varepsilon_{j}=\frac{\partial \ln f(x, t)}{\partial \ln x_{j}}=\beta_{j}$. Share of marginal product of input $\mathrm{j}$ is $\lambda_{j}=\frac{\varepsilon_{j}}{R T S}$, where $R T S=\sum_{j} \varepsilon_{j}$. The scale component $S C=(R T S-1) \sum_{j} \lambda_{j} \dot{x}_{j}$.

5) Allocative efficiency change can be found by $A E=\sum_{j} \dot{x}_{j}\left(\lambda_{j}-s_{j}\right)$ where $S_{j}$ can be directly calculated from the data if all price information is available.

\section{Data and empirical results}

The dataset used for this application is the Colombian Annual Manufacturers Survey (AMS) and covers the period 1982 to 1998 . Analysis of Colombian manufacturing industries is a relevant study for the decomposition of firm level productivity growth as Colombia underwent a substantial macroeconomic and market reform process. This decomposition study at the firm level should provide a policy guideline on the market reform process that can promote firm-level productivity growth.

The empirical analysis focuses on the Colombian meat, dairy products, bakery products, and confectionary industry indicated by 4 digit ISIC code 3111,3112, 3117, and 3119 respectively. These data are annual time-series observations for 93 meat manufacturing firms with 1032 observations, 99 dairy firms with a total of 1219 observations, 363 bakery firms with 4049 observations, and 46 chocolate and confectionary firms with 551 observations. The dataset contains annual plant-level information on the value of output and prices charged for each product; cost and prices paid for each material used; energy consumption in kilowatt per hour and energy prices; number of workers and payroll; and book values of capital stock (buildings, structures, 
machinery, and equipment). The AMS dataset is unique longitudinal data on plants in the sense that it has information on both plant-specific physical quantities and prices for both outputs and inputs. In contrast to most of the existing literature measuring productivity by deflating sales by an industry-level price index, these data eliminate a common source of measurement error in production function estimation. The detailed description of the data and variable construction used in this study are presented in Shee and Stefanou (2015). Table 1 presents a summary of the data used in this study where the means and standard deviations of the logarithm of plant-level physical quantity and price of output and input variables are presented. The units for energy consumption and labor use are kilowatt hours and hours of employment, respectively. Output, capital, and materials are expressed by thousands of pesos based on the constant price index for 1982 being 100. 
Table 1: Industry-wise summary statistics of key variables

\begin{tabular}{lccccc}
\hline Variables & $\begin{array}{c}\text { Butchering } \\
\text { and } \\
\text { meat canning }\end{array}$ & $\begin{array}{c}\text { Dairy } \\
\text { Products }\end{array}$ & $\begin{array}{c}\text { Bakery } \\
\text { products }\end{array}$ & $\begin{array}{c}\text { Cocoa, } \\
\text { chocolate and } \\
\text { confectionary }\end{array}$ & All Food \\
\hline Output & 11.582 & 12.035 & 9.779 & 10.637 & 10.976 \\
Capital & $(1.580)$ & $(1.673)$ & $(1.287)$ & $(1.937)$ & $(1.809)$ \\
Labor & 9.259 & 9.912 & 7.717 & 8.633 & 8.828 \\
Energy & $(1.655)$ & $(1.648)$ & $(1.558)$ & $(2.104)$ & $(1.949)$ \\
Materials & 11.244 & 11.541 & 10.508 & 10.956 & 10.881 \\
Output prices & $(1.239)$ & $(1.086)$ & $(1.015)$ & $(1.298)$ & $(1.198)$ \\
Energy prices & 12.404 & 13.195 & 11.183 & 11.362 & 12.211 \\
Material prices & $(1.580)$ & $(1.454)$ & $(1.186)$ & $(1.961)$ & $(1.719)$ \\
& 11.276 & 11.687 & 9.341 & 10.140 & 10.637 \\
No. of plants & $(1.695)$ & $(1.690)$ & $(1.252)$ & $(1.962)$ & $(1.857)$ \\
No. of obs. & -0.109 & -0.024 & 0.110 & 0.050 & 0.053 \\
\hline
\end{tabular}

\section{Estimation results}

The estimated coefficient of the stochastic production frontier parameter estimates using both the traditional and the endogeneity corrected methods are presented in Shee and Stefanou (2015). The results show that addressing the endogeneity issue is important in stochastic production frontier to generate consistent estimates of production parameters and technical efficiency. The estimate of capital coefficient is found to be consistently higher in endogeneity corrected method than in traditional stochastic frontier method for all four industries. Similarly point estimates of technical efficiency are higher in the endogeneity corrected method compared to the traditional stochastic 
frontier method. The average technical efficiency for all food industry firms is $62.1 \%$ and found to be deteriorating over time.

Productivity change occurs when the rate of output change is different from that of the index of inputs. Results regarding firm-level TFP growth and its components for the selected Colombian food manufacturing sectors are summarized by quintile in table 2 . Since the price information for labor and capital is unavailable we cannot calculate the allocative efficiency component. Following Kumbhakar and Lovell (2000) we assume the cost share of input j, $s_{j}=\frac{\varepsilon_{j}}{R T S}=\lambda_{j}$ (share of marginal product of input $\mathrm{j}$ ) for all $\mathrm{j}$, which serves to eliminate the allocative efficiency component. We are left with four possible components impacting productivity growth: technical progress, scale component, technical efficiency change, and learning effect.

The TFP growth rates vary greatly across firms and years. Most firms show positive productivity growth highest quintile values being $8.7 \%, 11.9 \%, 12.1 \%$, and $14.8 \%$ for meat, dairy, bakery, and confectionary product industries, respectively. Considering our Cobb-Douglas specification technical change component of productivity growth is the same across firms with an annual average of $2 \%, 1.8 \%, 1.2 \%$, and $1.4 \%$ for meat, dairy, bakery, and confectionary industries, respectively. Technical efficiency change $-\frac{\partial u}{\partial t}$ is interpreted as the rate at which an inefficient firm catches up to the production frontier. Technical efficiency of all the selected food industries in our study deteriorated throughout the sample period. Average growth rate of technical efficiency change consistently hovers around $1 \%$ resulting in a steady negative impact on productivity 
growth. Hence, policies that promote the efficient use of existing technology to catch up to the technology frontier in Colombian food manufacturing industry can be emphasized.

Given the modest point estimates of increasing returns to scale of production technology, the increased scale efficiency of the firms is resulting from the expanding scale of production. The change in scale component measures the effects of input changes on the output growth. Scale components are higher for confectionary and bakery sector and lower for meat and dairy sector. The positive scale effect suggests that productivity growth can be enhanced by scale component, whereas negative values imply that those firms are perhaps too large and already exceeded a size at which there is no scale economies.

The learning effects are directly calculated from the estimated residual of the endogeneity corrected stochastic frontier model and are found to vary widely across firms. For many firms, production experience yields information or knowledge, which improves decisions and results in productivity enhancement. On the other hand, organizational knowledge through experience can be embedded in individual workers, technology, and structure of the organization, consequently knowledge depreciation can happen for some firms due to labor turnover and obsolete technology within the firm (Argote, 1999; Benkard, 2000). Approximately 60\% of firms in the Colombian food sector show a positive learning effect with highest quintile values of LE being $6.8 \%, 8 \%$, $8.3 \%$, and $7.4 \%$ for meat, dairy, bakery, and confectionary product industries, respectively. Firms in the confectionary sector are found to have a comparatively higher learning effect than other food sectors. Table 3 presents a pairwise correlation between TFP growth, TEC, SC, and LE at the firm level. Although TEC, SC, and LE all have positive correlation with TFP growth, LE has the highest correlation with TFP growth for all the food sectors we examined. 
As noted by Oi (1967), Adler and Clark (1991), and Argote (1999), differences in learning efficiency across firms can be attributed to differences in training and infrastructure in Colombian food manufacturing firms. Food manufacturing industries are highly labor intensive, particularly in developing countries like Colombia. For example, meat production is one of the most laborintensive food processing operations, involving considerable hand-work to carve out specialty cuts, cleaning, applying sauces and flavoring, marinades etc. Hence, the meat producing firm's learning is embodied in their workers and labor turnover may lead to losses of experience for these firms. Argote (1999) finds that fast food firms are labor intensive (and subject to high labor turnover) and less technologically sophisticated; hence, they face a rapid knowledge depreciation compared to other industries. Benkard (2000) finds that unlearning or forgetting occurs as a result of labor turnover in the aircraft industry. To enhance productivity growth in Colombian food industry, learning gains must be improved considerably.

From table 2 we see that many firms in the lower quintiles have negative TFP growth which turns out to be a result of a negative learning effect. Thus, the decomposition framework in this study that allows for learning effect can explain and interpret empirical findings including negative and low TFP growth. 
Table 2: Firm level productivity growth decomposition for selected Colombian food manufacturing sectors

\begin{tabular}{|c|c|c|c|c|c|}
\hline & Quintile & $\begin{array}{l}\text { Butchering and } \\
\text { meat canning }\end{array}$ & $\begin{array}{c}\text { Dairy } \\
\text { Products }\end{array}$ & Bakery Products & $\begin{array}{r}\text { Chocolate and } \\
\text { confectionary }\end{array}$ \\
\hline \multirow[t]{5}{*}{ TFP growth } & 1 (lowest) & -0.060 & -0.026 & -0.044 & -0.041 \\
\hline & 2 & -0.011 & -0.004 & -0.009 & -0.008 \\
\hline & 3 & 0.006 & 0.008 & 0.010 & 0.013 \\
\hline & 4 & 0.030 & 0.034 & 0.034 & 0.053 \\
\hline & 5 (highest) & 0.087 & 0.119 & 0.121 & 0.148 \\
\hline \multirow[t]{5}{*}{ TEC } & 1 (lowest) & -0.011 & -0.011 & -0.011 & -0.012 \\
\hline & 2 & -0.010 & -0.012 & -0.011 & -0.013 \\
\hline & 3 & -0.009 & -0.011 & -0.010 & -0.013 \\
\hline & 4 & -0.011 & -0.010 & -0.009 & -0.009 \\
\hline & 5 (highest) & -0.008 & -0.010 & -0.010 & -0.011 \\
\hline \multirow[t]{5}{*}{ TP } & 1 (lowest) & 0.020 & 0.018 & 0.012 & 0.014 \\
\hline & 2 & 0.020 & 0.018 & 0.012 & 0.014 \\
\hline & 3 & 0.020 & 0.018 & 0.012 & 0.014 \\
\hline & 4 & 0.020 & 0.018 & 0.012 & 0.014 \\
\hline & 5 (highest) & 0.020 & 0.018 & 0.012 & 0.014 \\
\hline \multirow[t]{5}{*}{ SC } & 1 (lowest) & 0.005 & 0.004 & 0.005 & 0.017 \\
\hline & 2 & 0.002 & 0.008 & 0.011 & 0.006 \\
\hline & 3 & 0.003 & 0.012 & 0.015 & 0.011 \\
\hline & 4 & 0.009 & 0.014 & 0.023 & 0.034 \\
\hline & 5 (highest) & 0.007 & 0.031 & 0.036 & 0.071 \\
\hline \multirow[t]{5}{*}{$\mathbf{L E}$} & 1 (lowest) & -0.073 & -0.037 & -0.050 & -0.061 \\
\hline & 2 & -0.023 & -0.019 & -0.022 & -0.016 \\
\hline & 3 & -0.007 & -0.011 & -0.008 & 0.001 \\
\hline & 4 & 0.012 & 0.011 & 0.008 & 0.014 \\
\hline & 5 (highest) & 0.068 & 0.080 & 0.083 & 0.074 \\
\hline
\end{tabular}


Table 3: Pair-wise correlations of the decomposition components

\begin{tabular}{lcccc}
\hline Meat & TFP growth & TEC & SC & LE \\
\hline TFP growth & 1 & & & \\
TEC & 0.3187 & 1 & & \\
SC & 0.1732 & -0.1227 & 1 & \\
LE & 0.9899 & 0.2918 & 0.0417 & 1 \\
Dairy & & & & \\
TFP growth & 1 & & & \\
TEC & 0.2196 & 1 & & \\
SC & 0.4525 & -0.0876 & 1 & \\
LE & 0.9139 & 0.2441 & 0.0536 & 1 \\
Bakery & & & & \\
TFP growth & 1 & & & \\
TEC & 0.0597 & 1 & & \\
SC & 0.4173 & -0.101 & 1 & \\
LE & 0.815 & 0.0836 & -0.1848 & 1 \\
Confectionary & & & & \\
TFP growth & 1 & & & \\
TEC & 0.1735 & 1 & & \\
SC & 0.7077 & 0.1682 & 1 & \\
LE & 0.8504 & 0.0505 & 0.233 & 1 \\
\hline
\end{tabular}


Table 4: Industry-level average annual rates of TFP change

\begin{tabular}{lccccc}
\hline & Year & $\begin{array}{c}\text { Butchering and } \\
\text { meat canning }\end{array}$ & Dairy Products & Bakery Products & $\begin{array}{c}\text { Chocolate and } \\
\text { confectionary }\end{array}$ \\
\hline TFP growth & $1983-86$ & -0.016 & 0.018 & 0.001 & 0.028 \\
& $1987-90$ & 0.022 & 0.013 & 0.034 & 0.021 \\
& $1991-94$ & 0.024 & 0.007 & 0.014 & 0.025 \\
& $1995-98$ & 0.018 & 0.030 & 0.019 & 0.007 \\
\hline TEC & $1983-98$ & 0.012 & 0.017 & 0.017 & 0.020 \\
\hline SC & $1983-86$ & -0.009 & -0.010 & -0.009 & -0.010 \\
& $1987-90$ & -0.009 & -0.011 & -0.010 & -0.011 \\
& $1991-94$ & -0.010 & -0.011 & -0.011 & -0.012 \\
& $1995-98$ & -0.011 & -0.012 & -0.011 & -0.012 \\
& $1983-98$ & -0.010 & -0.011 & -0.010 & -0.011 \\
\hline LE & $1983-86$ & 0.008 & 0.012 & 0.017 & 0.016 \\
& $1987-90$ & 0.003 & 0.008 & 0.021 & 0.016 \\
& $1991-94$ & 0.005 & 0.018 & 0.022 & 0.044 \\
& $1995-98$ & 0.004 & 0.008 & 0.013 & 0.016 \\
& $1983-98$ & 0.005 & 0.012 & 0.018 & 0.023 \\
\hline & $1983-86$ & -0.036 & -0.002 & -0.019 & 0.008 \\
& $1987-90$ & 0.008 & -0.003 & 0.011 & 0.002 \\
& $1991-94$ & 0.009 & -0.018 & -0.010 & -0.021 \\
& $1995-98$ & 0.004 & 0.016 & 0.005 & -0.010 \\
& $1983-98$ & -0.003 & -0.002 & -0.003 & -0.005 \\
\hline
\end{tabular}

Table 4 presents the average annual industry-wise growth rate of TFP and its components over selected time periods. The industry-level annual scale efficiency change fluctuates considerably over the periods. Overall, average annual scale component is highest for the confectionary sector $(2.3 \%)$ and lowest for the meat sector $(0.5 \%)$. The scale efficiency for the four industries is very high during 1991-94 and becomes lower thereafter. Positive scale efficiency for all food sectors suggests the possible enhancement of scale efficiency through productivity enhancing investment. Technical efficiency change is negative and remains fairly steady over the 
sample years. All food industries examined here experience deteriorating technical efficiency over the sample period annual average TEC roughly being $-1 \%$. The Colombian meat industry can enhance productivity by focusing on improving technical efficiency. The industry-wise learning component varies considerably over years where the learning component was negative in 198386, then gradually increasing and positive in 1995-98 for meat, dairy, and bakery product sectors. In contrast, the LE was positive in 1983-86 and turned negative in 1995-98 for the confectionary sector. Overall, the industry-wise learning effects are smaller than those of SC, TEC and TP, with TP having the most significant influence. The calculated average TFP growth for the four food sectors varies widely across sample years. The overall annual TFP growth is highest $(2 \%)$ for confectionary sector while it is lowest $(1.2 \%)$ for meat sector. The productivity decomposition results show that positive TP is a key factor contributing to TFP growth, and $\mathrm{SC}$ and TP offset the decline in TEC and LE.

The productivity changes in Colombian food manufacturing firms over the 17- year period are explained by technical change, changes in technical efficiency, scale efficiency, and learning effect where all four components have significant influence on firm-level productivity growth. Thus, attributing changes in productivity to TP and TEC, as in previous stochastic frontier studies, may be misleading. This finding can improve decision-making by firm managers and ultimately improve productivity and performance by identifying the relative importance of productivity growth components. 


\section{Policy implications and conclusions}

By including the learning effect in firm-level productivity growth analyses, this study provides a theoretically consistent basis to evaluate the factors affecting productivity growth and their relative importance, which in turn increases the accuracy and policy relevance of productivity and firm performance. The decomposition of the productivity change has implications for efficient resource allocation within the firm. For firms where low TFP growth is a result of poor learning effect (or learning efficiency), the policy recommendation is to invest in training and infrastructure so that the firm can advance to the learning progress function of the 'best practice firm'. On the other hand, for firms where low-productivity growth results because of deteriorating technical efficiency, as we find in this study, the recommendation is to focus on improved managerial practices. The positive scale component at the firm level for Colombian food industry suggests the possible enhancement of scale efficiency through productivity enhancing investment. Similarly, for bakery and confectionary product firms where slow technological progress leads to low productivity growth, government policy should encourage investments that induce technological innovation to shift up the production frontier. Hence, the major policy implication of this study is identifying the relative importance of the firm-level productivity growth components.

Empirical results in this study indicate that the learning effect is a major contributor to TFP growth where there is evidence of both learning and unlearning (or forgetting) effects at the firm level in Colombian food manufacturing sector. Differences in learning across firms can be attributed to difference in training, quality of the personnel, and technological infrastructure in the firm. Hence, superior training that is grounded in research matters for developing human resource for the firm to gain better learning impact. Recent literature (Argote, et al., 1990; Darr, et al., 1995; Epple, et al., 1996; Benkard, 2000; Thompson, 2007; Brachet \& David, 2011) suggests that 
unlearning is the result of a mixture of firm- and employee-level experience depreciation. There can be manpower development policies oriented to building the expertise capacity in the community of the manufacturing facilities. These programs can serve to provide a stable, welltrained workforce to the employers, as well as being able to feed properly trained labor entrants as expertise departs. The consequence of deteriorating skills in the labor force is also a determinant of an 'unlearning' effect. For example, Brachet and David (2011) find skill decay and labor turnover are the result of unlearning where the former has half the magnitude of the later in the service sector. A remedy is for employers to institute a set of programs providing continuing education or refresher training.

The ability of an industry to be competitive supports the growth potential of firms. However, a definition of competitiveness focuses on the growth in returns to factors employed. More competitive firms will be able to draw expert labor away from less competitive firms. Thus, market forces can contribute to the observation of 'unlearning'. The extent to which this can happen depends of the distribution of competitive to less competitive firms within a region, the degree of labor mobility and to some extent on the relative competitiveness of one industry compared to others. No strong public policy remedies exist in these cases, beyond policies that remove nuisance barriers to firms operating in the economy. This study quantifies the components of firm level productivity growth that suggests policy recommendations in promoting productivity, but did not explore the sources resulting in those decomposition results. The factors considered in this research are not exhaustive in explaining productivity growth. With appropriate data availability we can further investigate on the determinants and their relative importance causing learning and unlearning effects. 


\section{Appendix A}

To solve the differential equation governing the learning progress for a general firm

$$
\begin{gathered}
\frac{d A}{d V}=\alpha A-\frac{\alpha}{\bar{a}} A^{2}-\eta A \\
\frac{d A}{d V}=\frac{\alpha}{\bar{a}} A\left((\alpha-\eta) \frac{\bar{a}}{\alpha}-A\right)
\end{gathered}
$$

Using separation of variables we get, $\int \frac{d A}{A\left((\alpha-\eta) \frac{\bar{a}}{\alpha}-A\right)}=\int \frac{\alpha}{\bar{a}} d V+c$

Partial fraction decomposition, $\frac{1}{(\alpha-\eta) \frac{\bar{a}}{\alpha}} \int\left(\frac{1}{A}-\frac{1}{(\alpha-\eta) \frac{\bar{a}}{\alpha}-A}\right) d A=\frac{\alpha}{\bar{a}} V+c$

$$
\begin{gathered}
\ln A-\ln \left((\alpha-\eta) \frac{\bar{a}}{\alpha}-A\right)=(\alpha-\eta) V+c \\
\frac{A}{(\alpha-\eta) \frac{\bar{a}}{\alpha}-A}=k e^{(\alpha-\eta) V}
\end{gathered}
$$

Initial condition, at $\mathrm{V}=0, A=a_{0}$ hence $k=\frac{a_{0}}{(\alpha-\eta) \frac{\bar{a}}{\alpha}-a_{0}}$

Putting the value of k we write, $(\alpha-\eta) \frac{\bar{a}}{\alpha} a_{0} e^{(\alpha-\eta) V}-a_{0} A e^{(\alpha-\eta) V}=A\left((\alpha-\eta) \frac{\bar{a}}{\alpha}-a_{0}\right)$

$$
A(V)=\frac{(\alpha-\eta) \frac{\bar{a}}{\alpha}}{1+\frac{(\alpha-\eta) \frac{\bar{a}}{\alpha}-a_{0}}{a_{0}} \exp \{-(\alpha-\eta) V\}}
$$

Substituting $\eta$ by $\eta \alpha$ the differential equation becomes $\frac{d A}{d V}=\alpha A-\frac{\alpha}{\bar{a}} A^{2}-\eta \alpha A$

and the solution becomes

$$
A\left(V_{t}\right)=\frac{(1-\eta) \bar{a}}{1+\frac{(1-\eta) \bar{a}-a_{0}}{a_{0}} e^{-\alpha(1-\eta) V}}
$$

\section{Appendix B}

Simulated plots of the learning progress function 


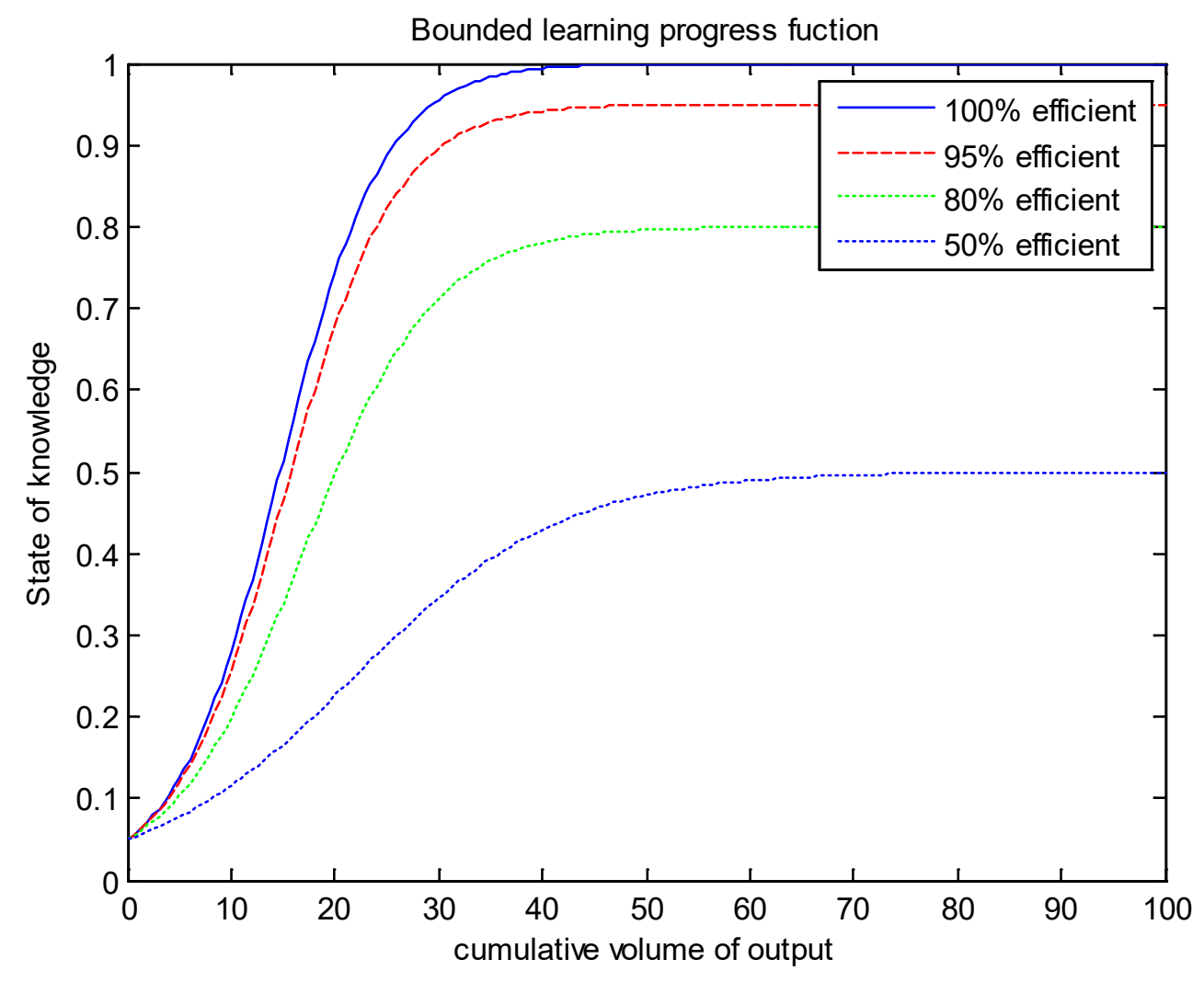

Figure B1: Simulated learning progress with different level of learning inefficiency 


\section{References}

Ackerberg, D., Caves, K., and Frazer, G. (2006). Structural identification of production functions. Munich Personal RePEc Archive Paper No. 38349, posted 25 April 2012, http://mpra.ub.uni-muenchen.de/38349/.

Ackerberg, D., Lanier Benkard, C., Berry, S., \& Pakes, A. (2007). Econometric tools for analyzing market outcomes. Handbook of econometrics, Elsevier, 6, 4171-4276.

Adler, P., \& Clark, K. (1991). Behind the learning curve: a sketch of the learning process. Management Science, 37(3), 267-281.

Argote, L. (1999). Organizational learning: Creating, retaining, and transferring knowledge: Kluwer Academic Publishers.

Argote, L., Beckman, S. L., \& Epple, D. (1990). The persistence and transfer of learning in industrial settings. Management Science, 36(2), 140-154.

Arrow, K. (1962). The economic implications of learning by doing. The review of economic studies, 29(3), 155-173.

Bahk, B., \& Gort, M. (1993). Decomposing learning by doing in new plants. The Journal of Political Economy, 101(4), 561-583.

Baloff, N. (1966). The Learning Curve--Some Controversial Issues. The Journal of Industrial Economics, 14(3), 275-282.

Baloff, N. (1971). Extension of the Learning Curve--Some Empirical Results. Operational Research Quarterly, 22(4), 329-340.

Battese, G., \& Coelli, T. (1992). Frontier production functions, technical efficiency and panel data: with application to paddy farmers in India. Journal of Productivity Analysis, 3(1), 153-169.

Bauer, P. (1990). Decomposing TFP growth in the presence of cost inefficiency, nonconstant returns to scale, and technological progress. Journal of Productivity Analysis, 1(4), 287299.

Benkard, C. (2000). Learning and forgetting: The dynamics of aircraft production. American Economic Review, 90(4), 1034-1054.

Brachet, T., \& David, G. (2011). On the Determinants of Organizational Forgetting. American Economic Journal: Microeconomics, 3(3), 100-123.

Carr, G. (1946). Peacetime cost estimating requires new learning curves. Aviation, 45(4), 220-228.

Cochran, E. (1960). New concepts of the learning curve. Journal of Industrial Engineering, 11(4), 317-327.

Cochran, E., \& Sherman, H. (1982). Predicting new product labour hours. International Journal of Production Research, 20(4), 517-543.

Conway, R., \& Schultz, A. (1959). The manufacturing progress function. Journal of Industrial Engineering, 10(1), 39-53. 
Darr, E. D., Argote, L., \& Epple, D. (1995). The acquisition, transfer, and depreciation of knowledge in service organizations: Productivity in franchises. Management Science, 41(11), 1750-1762.

Denny, M., Fuss, M., \& Waverman, L. (1981). The measurement and interpretation of total factor productivity in regulated industries, with an application to Canadian telecommunications. In T. G. Cowing \& R. E. Stevenson (Eds.), Productivity Measurement in Regulated Industries. New York: Academic Press.

Epple, D., Argote, L., \& Murphy, K. (1996). An empirical investigation of the microstructure of knowledge acquisition and transfer through learning by doing. Operations Research, 44(1), 77-86.

Griliches, Z., \& Mairesse, J. (1995). Production functions: the search for identification. NBER working paper 5067

Irwin, D., \& Klenow, P. (1994). Learning-by-doing spillovers in the semiconductor industry. The Journal of Political Economy, 102(6), 1200-1227.

Jarmin, R. (1994). Learning by doing and competition in the early rayon industry. Rand Journal of Economics, 25(3), 441-454.

Jovanovic, B., \& Nyarko, Y. (1995). A Bayesian learning model fitted to a variety of empirical learning curves. Brookings Papers on Economic Activity. Microeconomics, 247-305.

Kim, S., \& Han, G. (2001). A decomposition of total factor productivity growth in Korean manufacturing industries: A stochastic frontier approach. Journal of Productivity Analysis, 16(3), 269-281.

Kumbhakar, S. C. (2000). Estimation and decomposition of productivity change when production is not efficient: a panel data approach. Econometric Reviews, 19(4), 425-460.

Kumbhakar, S. C., \& Lovell, C. A. K. (2000). Stochastic Frontier Analysis: Cambridge University Press.

Leibenstein, H. (1966). Allocative efficiency vs." X-efficiency". The American Economic Review, 56(3), 392-415.

Leibenstein, H. (1978). X-inefficiency Xists: Reply to an Xorcist. The American Economic Review, 68(1), 203-211.

Leibenstein, H. (1979). A branch of economics is missing: micro-micro theory. Journal of Economic Literature, 17(2), 477-502.

Levinsohn, J., \& Petrin, A. (2003). Estimating production functions using inputs to control for unobservables. Review of Economic Studies, 70(2), 317-341.

Lieberman, M. (1984). The learning curve and pricing in the chemical processing industries. The Rand Journal of Economics, 15(2), 213-228.

Lucas Jr, R. (1993). Making a miracle. Econometrica, 61(2), 251-272.

Luh, Y., \& Stefanou, S. (1993). Learning-by-doing and the sources of productivity growth: A dynamic model with application to US agriculture. Journal of Productivity Analysis, 4(4), 353-370.

Malerba, F. (1992). Learning by firms and incremental technical change. The Economic Journal, 102(413), 845-859.

Marschak, J., \& Andrews, W. (1944). Random simultaneous equations and the theory of production. Econometrica, 12(3), 143-205.

Mundlak, Y. (1996). Production function estimation: Reviving the primal. Econometrica, 64(2), 431-438. 
Nishimizu, M., \& Page, J. M. (1982). Total factor productivity growth, technological progress and technical efficiency change: dimensions of productivity change in Yugoslavia, 1965-78. The Economic Journal, 92(368), 920-936.

Oi, W. Y. (1967). The Neoclassical Foundations of Progress Function. The Economic Journal, 77(307), 579-594.

Olley, G., \& Pakes, A. (1996). The dynamics of productivity in the telecommunications equipment industry. Econometrica, 64(6), 1263-1297.

Rapping, L. (1965). Learning and World War II production functions. The Review of Economics and Statistics, 47(1), 81-86.

Rosen, S. (1972). Learning by experience as joint production. The Quarterly Journal of Economics, 86(3), 366-382.

Shee, A. and Stefanou, S.E. (2015). Endogeneity corrected stochastic production frontier and technical efficiency. American Journal of Agricultural Economics, 97(3), 939-952.

Stefanou, S.E., \& Saxena, S. (1988). Education, experience, and allocative efficiency: a dual approach. American Journal of Agricultural Economics, 70(2), 338-345.

Stigler, G. (1976). The Xistence of X-efficiency. The American Economic Review, 66(1), 213-216.

Thompson, P. (2001). How much did the liberty shipbuilders learn? New evidence for an old case study. Journal of Political Economy, 109(1), 103-137.

Thompson, P. (2007). How much did the Liberty shipbuilders forget? Management Science, 53(6), 908-918.

Thornton, R., \& Thompson, P. (2001). Learning from experience and learning from others: An exploration of learning and spillovers in wartime shipbuilding. The American Economic Review, 91(5), 1350-1368.

Young, A. (1993). Invention and bounded learning by doing. The Journal of Political Economy, 101(3), 443-472. 